\title{
Association of apolipoprotein E polymorphism with plasma lipids and Alzheimer's disease in a Southern Brazilian population
}

F.M. de-Andrade ${ }^{1}$, M. Larrandaburu ${ }^{1}$, S.M. Callegari-Jacques²,

G. Gastaldo ${ }^{3}$ and M.H. Hutz ${ }^{1}$

\author{
${ }^{1}$ Departamento de Genética, Instituto de Biociências, and \\ 2Departamento de Estatística, Instituto de M atemática, \\ Universidade Federal do Rio Grande do Sul, Porto Alegre, RS, Brasil \\ 3Unidade de Bioquímica, Serviço de Patologia Clínica, \\ Hospital de Clínicas de Porto Alegre, Porto Alegre, RS, Brasil
}

\section{Correspondence \\ M.H. Hutz \\ Departamento de Genética Instituto de Biociências, UFRGS \\ Caixa Postal 15053 \\ 91501-970 Porto Alegre, RS \\ Brasil \\ Fax: +55-51-319-2011 \\ E-mail: jade@ if.ufrgs.br}

Research supported by FINEP (No. 66.96.0617.00), PRONEX (No. 76.97.0996.00), CN Pq (No. 520105/96-2) and FAPERGS (No. 96/0607.9). F.M. de-Andrade is the recipient of a CAPES fellowship.

Received May 13, 1999

Accepted February 8, 2000

\section{Abstract}

Apolipoprotein E (protein: apo E; gene: $A P O E$ ) plays an important role in the multifactorial etiology of both Alzheimer's disease (AD) and lipid level concentrations. The polymerase chain reaction (PCR) was used to investigate the $A P O E$ gene polymorphism in 446 unrelated Caucasians, among them 23 AD patients, and 100 Afro-Brazilians living in Porto Alegre, Brazil. The frequencies of the $A P O E^{*} 2$, $A P O E^{*} 3$ and $A P O E^{*} 4$ alleles were $0.075,0.810$ and 0.115 in Caucasians and $0.075,0.700$ and 0.225 in Afro-Brazilians, respectively $\left(\chi^{2}\right.$ $=8.72, \mathrm{P}=0.013)$. A highly significant association was observed between the $A P O E^{*} 4$ allele and $\mathrm{AD}$ in this population-based sample. The $A P O E^{*} 4$ frequency in $\mathrm{AD}$ patients $(39 \%)$ was about four times higher than in the general Caucasian population (11.5\%). The influence of each of the three common $A P O E$ alleles on lipid traits was evaluated by the use of the average excess statistic. The $E^{*} 2$ allele is associated with lower levels of triglycerides and of total and non-HDL cholesterol in both men and women. Conversely, the $E^{*} 4$ allele is associated with higher levels of these traits in women only. The effect of $A P O E$ alleles was of greater magnitude in women.
Key words

- Polymorphism

- APOE

- Lipoproteins

- Apoprotein

- Alzheimer's disease

\section{Introduction}

Apolipoprotein E (protein: apo E; gene: $A P O E$ ) has a major physiological role in the regulation of overall lipid homeostasis (1) and also plays an important role in neuronal repair (2). The structural locus of $A P O E$ has three common alleles designated $E^{*} 2, E^{*} 3$ and $E^{*} 4$, which code for three protein isoforms (E2, E3 and E4). APOE*3 is the most frequent allele in all populations studied to date (3). These isoforms have been shown to influence serum lipid levels (4-7), cardiovascular disease risk $(8,9)$ as well as the risk for developing Alzheimer's disease (AD) $(10,11)$, with $A P O E^{*} 2$ and $A P O E^{*} 4$ most often having opposite effects.

Due to their clinical significance, it is very important to know the distribution of $A P O E$ alleles in different populations in order to determine if this polymorphism has a universal effect on lipid levels and on the risk 
for developing $\mathrm{AD}$ or whether this effect is modulated by genetic-environmental interactions.

The aims of the present investigation were to describe $A P O E$ allele frequencies and to investigate the effect of this polymorphism on serum lipid levels and AD in a Southern Brazilian population.

\section{Material and Methods}

\section{Subjects}

Porto Alegre is the capital of Brazil's southernmost state; the city was founded in 1752 by 60 white couples from the Azores Islands. At present the Caucasians from Porto Alegre are still mainly of Portuguese descent, but Italians, Spaniards and Germans have also contributed to its gene pool. Blacks constitute approximately $14 \%$ of the population. They are descendants of slaves who were brought to Brazil between the fifteenth and eighteenth centuries mainly from Africa's West Coast, but also from Angola and Mozambique.

Three independent samples of Caucasian individuals were studied. One hundred subjects were ascertained at the Genetics Department of the Federal University of Rio Grande do Sul where they came for paternity testing, their mean age being $31 \pm 11.5$ years. These individuals constitute a random sample from the population and were employed to determine the $A P O E$ allele frequencies in the population and as controls for the probable Alzheimer's disease group. Twentythree patients with a diagnosis of probable Alzheimer's disease, according to the NINCDS-ADRDA criteria (12) were recruited at the Neurology Service, Hospital de Clínicas de Porto Alegre. All cases were sporadic and their ages ranged from 61 to 84 years (mean age, $72.3 \pm 3.3$ years). In order to determine the effect of $A P O E$ polymorphism on serum lipids a sample of 343 individuals was collected at the Biochemistry
Unit, Hospital de Clínicas de Porto Alegre, to which they went for routine blood determinations (mean age, $57 \pm 13.1$ years).

The sample of Blacks $(\mathrm{N}=100)$ was ascertained at the Central Laboratory of the Santa Casa de Misericórdia de Porto Alegre, their mean age being $35 \pm 15.2$ years.

Informed consent was obtained from patients, relatives or their legal tutors in all cases.

\section{Lipid analyses}

Total cholesterol, HDL cholesterol and triglycerides were determined enzymatically with commercial kits $\left(\right.$ Merck $^{\circledR}$, Darmstadt, Germany) on a MegaMerck ${ }^{\circledR}$ autoanalyser from the 343 subjects ascertained at Hospital de Clínicas de Porto Alegre, after a 12-h fast.

To evaluate the effect of $A P O E$ genotypes on lipid values, the subjects were classified according to Chamberlain et al. (13) as hypercholesterolemic (total plasma cholesterol $>300 \mathrm{mg} / \mathrm{dl}$ ), normolipidemic (total cholesterol $<200 \mathrm{mg} / \mathrm{dl}$ and serum triglycerides $<182 \mathrm{mg} / \mathrm{dl}$ ) and hypertriglyceridemic (plasma triglyceride levels $>350 \mathrm{mg} / \mathrm{dl}$ ). Sixty-two individuals were not included in this analysis because they did not meet these criteria, while 25 individuals had both hypercholesterolemia and hypertriglyceridemia and were included in the study.

\section{DNA analyses}

DNA was extracted from the blood samples by a salting out procedure (14). DNA was amplified by the PCR reaction, using the same conditions and oligonucleotide primers as described previously (15). The amplification products were subsequently digested with $H$ haI under the conditions recommended by the manufacturer (Life Technologies Inc., Grand Island, NY, USA). Genotypes were determined after electrophoresis on $4 \%$ agarose gels containing ethidium bromide, using a 10-bp ladder to score the band sizes. 


\section{Statistical analysis}

Allele frequencies were estimated by the gene-counting method. A $\chi^{2}$ test for goodness of fit was used to verify whether the observed allele frequencies agreed with those expected under the hypothesis of HardyWeinberg equilibrium. Heterogeneity among groups was tested by the $\chi^{2}$ of Roff and Bentzen for small samples (16).

Linear regression analysis was used to adjust serum lipid concentrations for the effect of age and sex. Differences for lipids among adjusted means by genotype were evaluated by ANOVA. Equality of variances was tested by the method of Levene; when variances were unequal, the non-parametric Kruskal-Wallis test was employed. Triglyceride levels were log transformed to remove skewness. Analyses were performed using the SPSS/PC software.

The average excess of the three alleles in the population at large at each gender and age-adjusted level was estimated according to the formula

$$
\mathrm{a}_{\mathrm{i}}=\sum_{k=1}^{k}\left[f_{i k} / p_{i}\right]\left[\bar{y}_{i k}-\bar{y}\right], i=1, \ldots, k
$$

where $\bar{y}_{i k}$ is the mean of the phenotype for individuals with genotype $i k, \bar{y}$ is the mean of the phenotype for the population, $f_{i k}$ is the frequency of the ordered genotype $i k$, and $p_{i}$ is the frequency of allele $i(17)$.

\section{Results}

\section{APO E genotype and allele frequencies in normal individuals and in patients with Alzheimer's disease}

To establish a population baseline, $A P O E$ allele and genotype frequencies were determined in 100 unrelated Caucasian individuals randomly chosen among those presenting for paternity tests and in the 100 AfroBrazilians investigated (Table 1). Both samples were in Hardy-Weinberg equilibrium. The most common genotype in Brazilian Caucasians and Blacks was $E^{*} 3 / E^{*} 3$, followed by $E^{*} 3 / E^{*} 4$ heterozygotes. The distribution of $A P O E$ alleles between the two ethnic groups was significantly heterogeneous $(\mathrm{P}=0.013)$. The relative frequency of the $E^{*} 4$ allele $(22.5 \%)$ was higher in AfroBrazilians than in Brazilian Caucasians (11.5\%; Table 1).

Due to the ethnic difference in allele frequencies observed in this population survey, the $A D$ patients, all Caucasians, were compared with the Caucasian sample as controls (Table 1). Approximately $60 \%$ of the $\mathrm{AD}$ patients had at least one $E^{*} 4$ allele. The prevalence of this allele (39\%) was four times higher in the $\mathrm{AD}$ group than in controls (11.5\%). This difference was highly significant $(\mathrm{P}<0.001)$.

\section{Lipid association study}

Table 2 shows the allele and genotype frequencies observed among the 343 individuals investigated for lipid levels. Genotype and allele frequencies from this sample

Table 1 - APOE genotype and allele frequencies in healthy and Alzheimer's disease individuals from a Southern Brazilian population.

Data are reported as percent. AD, Alzheimer's disease Caucasian patients. $\chi^{2}=8.72 ; \mathrm{P}=0.013$ (between the ethnic groups). $\chi^{2}=20.65 ; \mathrm{P}<0.001$ (between $\mathrm{AD}$ patients and Caucasian controls).

\begin{tabular}{|c|c|c|c|}
\hline & $\begin{array}{c}\text { Blacks } \\
(\mathrm{N}=100)\end{array}$ & $\begin{array}{c}\text { Caucasians } \\
(\mathrm{N}=100)\end{array}$ & $\begin{array}{c}A D \\
(N=23)\end{array}$ \\
\hline \multicolumn{4}{|c|}{ Genotypes } \\
\hline$E * 2 / E * 2$ & 0 & 1 & 0 \\
\hline$E * 2 / E * 3$ & 13 & 10 & 4 \\
\hline$E * 2 / E * 4$ & 2 & 3 & 9 \\
\hline$E * 3 / E * 3$ & 50 & 68 & 35 \\
\hline$E * 3 / E * 4$ & 27 & 16 & 35 \\
\hline$E * 4 / E * 4$ & 8 & 2 & 17 \\
\hline \multicolumn{4}{|l|}{ Alleles } \\
\hline$E * 2$ & 7.5 & 7.5 & 7.0 \\
\hline$E * 3$ & 70.0 & 81.0 & 54.0 \\
\hline$E * 4$ & 22.5 & 11.5 & 39.0 \\
\hline
\end{tabular}


did not differ from those obtained for the random Caucasian sample (Table 1). Although the difference was not significant, the $E^{*} 2$-containing genotypes were somewhat less frequent in hypercholesterolemics $(9.7 \%)$ and hypertriglyceridemics $(9.5 \%)$ than in normolipidemics (17.6\%), while $\mathrm{APOE}^{*} 4$ carriers were less prevalent in normolipidemics $(18 \%)$ than in hypercholesterolemics and hypertriglyceridemics ( 24 and $28 \%$, respectively).
The mean lipid levels adjusted by $A P O E$ genotype are given in Table 3 . Since very few subjects had the $E^{*} 2 / E^{*} 2$ or $E^{*} 4 / E^{*} 4$ genotype, subjects were regrouped into $E^{*} 2$ carriers $\left(E^{*} 2 / E^{*} 2\right.$ and $\left.E^{*} 2 / E^{*} 3\right), E^{*} 3 / E^{*} 3$ and $E^{*} 4$ carriers $\left(E^{*} 3 / E^{*} 4\right.$ and $\left.E^{*} 4 / E^{*} 4\right)$. Individuals with the $E^{*} 2 / E^{*} 4$ genotype $(\mathrm{N}=$ 5 ) could not be assigned to any of the groups and were therefore excluded from this analysis. A significant directional variation was seen among the three groups for triglycer-

Table 2 - Genotype and allele frequencies of APOE in normolipidemics, hypercholesterolemics and hypertriglyceridemics from a Southern Brazilian population*.

$\chi^{2}=3.58 ; \mathrm{P}=0.059$ (hypercholesterolemics versus controls (comparison between carriers and non-carriers of the APOE*2 allele)). $\chi^{2}=1.44 ; \mathrm{P}=0.231$ (hypercholesterolemics versus controls (comparison between carriers and non-carriers of the APOE $* 4$ allele)). $\chi^{2}=1.601 ; \mathrm{P}=0.206$ (hypertriglyceridemics versus controls (comparison between carriers and non-carriers of the APOE* 2 allele)). $\chi^{2}=1.640 ; \mathrm{P}=0.200$ (hypertriglyceridemics versus controls (comparison between carriers and non-carriers of the APOE* 4 allele)). *From the 343 individuals studied, 62 were not included in any group and 25 subjects with hypertriglyceridemia and hypercholesterolemia were included in both groups.

\begin{tabular}{|c|c|c|c|c|c|c|c|c|}
\hline & \multicolumn{2}{|c|}{$\begin{array}{l}\text { Hypercholesterolemics } \\
\qquad(\mathrm{N}=134)\end{array}$} & \multicolumn{2}{|c|}{$\begin{array}{l}\text { Controls } \\
(\mathrm{N}=130)\end{array}$} & \multicolumn{2}{|c|}{$\begin{array}{l}\text { Hypertriglyceridemics } \\
\qquad(\mathrm{N}=42)\end{array}$} & \multicolumn{2}{|c|}{$\begin{array}{l}\text { Total sample } \\
\qquad(\mathrm{N}=343)\end{array}$} \\
\hline & $\mathrm{N}$ & $\%$ & $\mathrm{~N}$ & $\%$ & $N$ & $\%$ & $N$ & $\%$ \\
\hline \multicolumn{9}{|l|}{ Genotypes } \\
\hline$E * 2 / E * 2$ & 1 & 0.7 & 2 & 1.5 & 1 & 2.4 & 2 & 0.6 \\
\hline$E * 2 / E * 3$ & 10 & 7.5 & 19 & 14.6 & 3 & 7.1 & 38 & 11.1 \\
\hline$E * 2 / E * 4$ & 2 & 1.5 & 2 & 1.5 & 0 & 0 & 5 & 1.4 \\
\hline$E * 3 / E * 3$ & 89 & 66.4 & 84 & 64.6 & 26 & 61.9 & 221 & 64.4 \\
\hline$E * 3 / E * 4$ & 31 & 23.1 & 23 & 17.7 & 11 & 26.2 & 75 & 21.9 \\
\hline$E * 4 / E * 4$ & 1 & 0.7 & 0 & 0 & 1 & 2.4 & 2 & 0.6 \\
\hline \multicolumn{9}{|l|}{ Alleles } \\
\hline E*2 & & 7.5 & & 9.6 & & 5.9 & & 6.9 \\
\hline$E * 3$ & & 81.0 & & 80.8 & & 78.6 & & 80.9 \\
\hline$E * 4$ & & 11.5 & & 9.6 & & 15.5 & & 12.2 \\
\hline
\end{tabular}

Table 3 - Adjusted lipid levels of 338 individuals from Porto Alegre classified by APOE genotype*.

Data are reported as means ( $\pm S D$ ). ${ }^{1}$ Kruskal-Wallis test; ${ }^{2} \mathrm{ANOVA}$. ${ }^{*}$ Five $E * 2 / E * 4$ carriers were not included in this analysis. $\mathrm{TC}=$ Total cholesterol; $\mathrm{HDL}-\mathrm{C}=\mathrm{HDL}$ cholesterol.

\begin{tabular}{lcccc}
\hline & $\begin{array}{c}\mathrm{E}^{*} 2 / \mathrm{E}^{*} 2+\mathrm{E}^{*} 2 / \mathrm{E}^{* 3} \\
(\mathrm{~N}=40)\end{array}$ & $\begin{array}{c}\mathrm{E} * 3 / \mathrm{E}^{* 3} \\
(\mathrm{~N}=221)\end{array}$ & $\begin{array}{c}\mathrm{E}^{*} 4 / \mathrm{E}^{*} 4+\mathrm{E}^{* 3 / E * 4} \\
(\mathrm{~N}=77)\end{array}$ & $\mathrm{P}$ \\
\hline $\mathrm{TC}(\mathrm{mg} / \mathrm{dl})$ & $222.6(71.9)$ & $250.2(81.1)$ & $251.0(72.1)$ & $0.08^{1}$ \\
$\mathrm{HDL}-\mathrm{C}(\mathrm{mg} / \mathrm{dl})$ & $44.5(14.0)$ & $46.1(13.0)$ & $45.1(16.8)$ & $0.75^{2}$ \\
Non-HDL-C $(\mathrm{mg} / \mathrm{dl})$ & $177.5(72.2)$ & $202.4(80.4)$ & $202.4(69.4)$ & $0.14^{1}$ \\
Triglycerides $(\mathrm{mg} / \mathrm{dl})$ & $177.0(129.5)$ & $211.5(80.4)$ & $243.9(204.5)$ & $0.048^{2}$
\end{tabular}


ides, with $A P O E^{*} 2$ carriers showing the lowest levels and $A P O E^{*} 4$ carriers the highest levels. Although the difference was not statistically significant, the mean levels of total cholesterol and non-HDL cholesterol were also somewhat lower in the $E^{*} 2$ group but were not increased relative to $E^{*} 3$ homozygotes among the $E^{*} 4$ carriers. No specific trend was observed for HDL cholesterol.

The estimates of average excess for each of the three common $A P O E$ alleles for total cholesterol, non-HDL cholesterol and triglycerides are presented in Figure 1. The effect of the $E^{*} 3$ allele on lipid levels was negligible because the mean values of subjects carrying this allele was indistinguishable from the population mean. In this sample, the effect of $E^{*} 2$ was to lower total cholesterol, non-HDL cholesterol and triglycerides. This was true for both men and women, although the magnitude of this difference was more pronounced in women. Conversely, $E^{*} 4$ was associated with higher lipid levels, but in women only. The range of effects of the $E^{*} 4$ allele was less than that of the $E^{*} 2$ allele (Figure 1).

\section{Discussion}

Data on distribution of $A P O E$ genotypes are highly heterogeneous in terms of frequency among populations $(3,4,18)$. European populations have been widely studied for $A P O E$ polymorphism. One of the most important findings of these investigations is a clear north to south decreasing gradient of the $E^{*} 4$ allele frequency in continental western Europe, with an opposite direction for the $E^{*} 3$ allele. The prevalence of $E^{*} 4$ is above $20 \%$ in Finland and Sweden $(4,19)$ and below $8 \%$ in the Iberian Peninsula (20). No clinal pattern is apparent for $E^{*} 2$ frequencies (21). The $A P O E$ allele prevalences observed in the present study on Southern Brazilian Caucasians are similar to those found for Southern Europeans $(19,20,22)$, as expected if we consider the European origin of our population. Much less information is available for African populations $(4,18,23$, 24). The cited investigations reported a higher prevalence of $E^{*} 4$ (range $24-30 \%$ ) and a lower $E^{*} 3$ frequency relative to Caucasians. The Afro-Brazilian sample studied herein had a slightly lower $E^{*} 4$ prevalence probably due to miscegenation (22.5\%; Table 1$)$. Bortolini et al. (25) estimated a $46 \%$ contribution of Caucasian genes to this population of African origin. These results indicate the need for more population studies at this locus to avoid false-positive or -negative re-
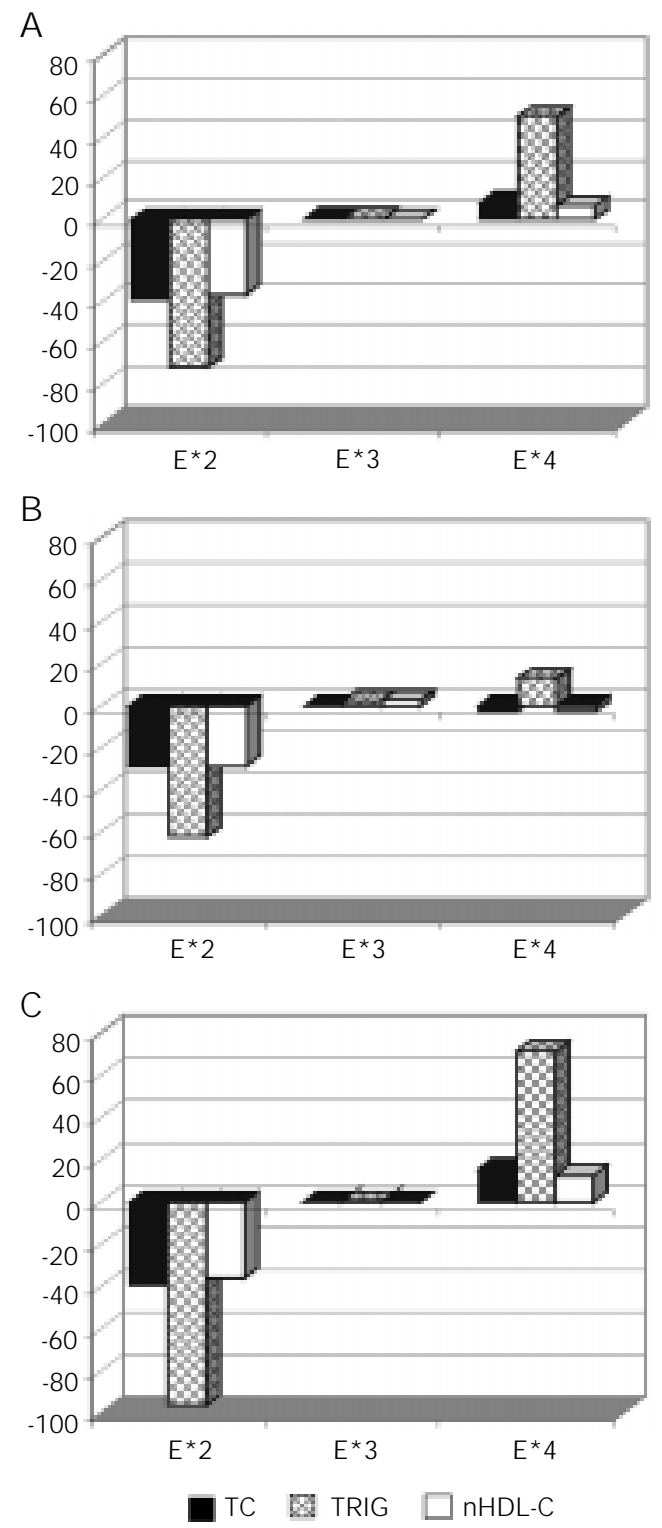

Figure 1 - Average excess of the APOE alleles $(\mathrm{mg} / \mathrm{dl})$ in total sample (A), men only (B), and women only (C). TC - Total cholesterol; TRIG - triglycerides; nHDL-C - non-HDL cholesterol. 
sults in association studies with unmatched ethnic controls.

Strittmatter et al. (10) reported the association of $\mathrm{APOE}^{*} 4$ with late onset familial AD. Saunders et al. (26) extended this association to sporadic AD patients detected at autopsy. These data have been confirmed and extended to AD groups in several populations. However, a meta-analysis including 47 case-control investigations concluded that the $E^{*} 4 / \mathrm{AD}$ association in African-Americans and Hispanics requires clarification and should be investigated further (27). In our admittedly very small sample of Brazilians of European ancestry with AD, this association was highly significant $(\mathrm{P}<0.001$; Table 1). These results agree with those observed elsewhere (27) in individuals from this ethnic group.

Several investigations in Europe and in North America have suggested that the risk of death is associated with $A P O E$ isoforms. The relative frequency of $A P O E^{*} 4$ was decreased and that of $A P O E^{*} 2$ was higher in the oldest subjects (octogenarians, nonagenarians and centenarians) compared to normal subjects of a younger age group (28-30).

Based on the fact that coronary artery disease builds up in a progressive fashion, representing the principal cause of mortality with aging, Haviland et al. (30) suggested that this finding is consistent with the hypothesis that genetic variation in $A P O E$ influences variation in the risk of coronary artery disease. In their sample of octogenarians the relative frequency of $A P O E^{*} 4$ was reduced.

Corder et al. (31) quantified the influence of $A P O E$ on survival in a population sample of 1077 subjects aged 75 or older. The main results of this investigation were: 1) The mortality of subjects with the $A P O E^{*} 2 /$ $E^{*} 3$ genotype was half that of subjects who carried the $A P O E^{*} 3 / E^{*} 3$ genotype. 2) The mortality of subjects with the $A P O E^{*} 3 / E^{*} 4$ genotype was twice that of subjects who carried the $A P O E^{*} 3 / E^{*} 3$ genotype. 3) Using Kaplan-Meier plots and Cox regression mod- els which controlled for age and sex, these authors showed that $A P O E$ polymorphism did not predict mortality in subjects initially aged 75 through 84 years, but there were significant differences in survival by genotype among subjects aged 85 years or older. 4) The mean survival difference was 1.9 years ( 4.9 years for the $A P O E^{*} 2 / E^{*} 3$ genotype versus 3.0 years for the $A P O E^{*} 3 / E^{*} 4$ genotype). 5) There were no differences in survival among cognitively impaired subjects aged 85 years or older.

The age of our Alzheimer's disease subjects ranged from 61 to 84 years. If a bias were present in terms of age of the Caucasian sample, with a mean age of 31 , it would be in the opposite direction favoring the $A P O E^{*} 2$ proportion, a fact that was not observed (7.5\% among Caucasians and $7.0 \%$ among Alzheimer's disease patients; Table 1). No differences were observed because the differential survival rate described was significant only in subjects 85 or older with good cognition. Therefore, we may conclude that the relatively higher frequency of $\mathrm{APOE}^{*} 4$ allele is due to Alzheimer's disease, as was observed in the meta-analysis reported by Farrer et al. (27).

Although $A P O E$ allele distributions are heterogeneous, the relation of alleles with plasma cholesterol is found to be similar among populations (4). However, the amplitude of the effect may be modulated by ethnic background and environmental factors $(7,32)$. In the present study, associations of $A P O E$ genotypes with serum lipids were consistent with the well-identified effects of APOE (33-35). Several studies have shown that the effect of $E^{*} 2$ in reducing cholesterol levels is two- to four-fold the increasing effect of $E^{*} 4(4,5,36)$, whereas similar effects of both alleles have also been reported $(37,38)$. In Brazilian Caucasians the influence of $E^{*} 2$ was greater than that of $E^{*} 4$. The most plausible reasons for these inconsistencies are differences in statistical treatment, different sampling schemes or differ- 
ent environmental factors. It is likely that the influence of the $A P O E$ gene on serum lipid levels may be modified by other genetic or environmental factors among different populations $(7,32)$.

Whereas the $A P O E$ effects on serum cholesterol levels are almost constant in most populations, there are controversial results about these effects on triglyceride levels. $E^{*} 2$ has been associated with higher levels $(5,23,35,38-40)$ and lower levels $(6,33)$ relative to $E^{*} 3$ and $E^{*} 4$. Our study shows higher triglyceride concentrations in $E^{*} 4$ carriers than in $E^{*} 2$ carriers. The $E^{*} 2$ allele has been associated with some degree of impaired clearance of triglyceride-rich chylomicrons and VLDL remnants (41), while other studies have suggested that patients with type $\mathrm{V}$ hyperlipoproteinemia have an overrepresentation of the $E^{*} 4$ allele which may contribute to hypertriglyceridemia (42). Clearly more data are needed to understand the relationship of $A P O E$ and triglyceride levels.

The average excess of the common $A P O E$ alleles reported here is in agreement with previous studies $(4,5,38)$. The effect of $A P O E$ alleles on lipid levels was more pronounced in women (Figure 1). These results suggest that sex-specific hormones act as important regulators on these complex metabolic pathways as discussed by Robitaille et al. (38) and Schaefer et al. (43). Additional studies on the interaction of hormones, genes and lipids in women are needed to understand how hormones influence the effects of $A P O E$ alleles on lipids.

\section{Acknowledgments}

Thanks are due to Prof. Francisco M. Salzano for help in obtaining access to the Caucasoid control samples and for revising the manuscript. The Afro-Brazilian sample was recruited by Elisa M. Heidrich and Maria Catira Bortolini. Sample collection and extraction of DNA from hyperlipidemic and normolipidemic subjects was performed with the help of Andre F. Vargas and Marilu Fiegenbaum. We are also grateful to the staff of the Neurology Service, Hospital de Clínicas de Porto Alegre, mainly to Dr. Marcia L.F. Chaves, for referral of the AD patients.

\section{References}

1. Mahley RW (1988). Apolipoprotein E: cholesterol transport protein with expanding role in cell biology. Science, 240: 622630.

2. Rubinsztein DC (1995). Apolipoprotein E: a review of its roles in lipoprotein metabolism, neuronal growth and repair as a risk for Alzheimer's disease. Psychological Medicine, 25: 223-229.

3. Gerdes LU, Gerdes C, Hansen PS, Klausen IC, Færgeman O \& Dyerberg J (1996). The apolipoprotein E polymorphism in Greenland Inuit in its global perspective. Human Genetics, 98: 546-550.

4. Hallman DM, Boerwinkle E, Saha N, Sandholzer C, Menzel HJ , Csázár A \& Utermann G (1991). The apolipoprotein $\mathrm{E}$ polymorphism: a comparison of allele frequencies and effects in nine populations. American J ournal of Human Genetics, 49: 338-349.
5. Kamboh MI, Aston CE \& Hamman RF (1995). The relationship of APOE polymorphism and cholesterol levels in normoglycemic and diabetic subjects in a biethnic population from San Luis Valley, Colorado. Atherosclerosis, 112: 145-159.

6. Mahley RW, Palaoglu KE, Atak Z, DawsonPepin J, Langlois A, Cheung V, Onat H, Fulks P, Mahley L, Vakar F, Osbayrak S, Gökdemir O \& Winkler W (1995). Turkish Heart Study: lipids, lipoproteins, and apolipoproteins. J ournal of Lipid Research, 36: 839-859.

7. Boer J MA, Feskens EJ M, Schouten EG, Havekes LM, Seidell J C \& Kromhout D (1998). Lipid profiles reflecting high and low risk for coronary heart disease: contribution of apolipoprotein E polymorphism and lifestyle. Atherosclerosis, 136: 395402.

8. Tiret L, De Knijff P, Menzel H, Ehnholm C,
Nicaud V \& Havekes LM (1994). ApoE polymorphism and predisposition to coronary heart disease in youths of different European populations - The EARS study. Arteriosclerosis and Thrombosis, 14: 1617-1624.

9. Moore J H, Reilly SL, Ferrel RE \& Sing CF (1997). The role of the apolipoprotein $E$ polymorphism in the prediction of coronary artery disease age of onset. Clinical Genetics, 51: 22-25.

10. Strittmatter WJ , Saunders AM \& Schmechel D (1993). Apolipoprotein E: High affinity binding to $ß A$ amyloid and increased frequency of type 4 allele in familial Alzheimer's disease. Proceedings of the National Academy of Sciences, USA, 90: 1977-1981.

11. Lendon CL, Ashall F \& Goate AM (1997). Exploring the etiology of Alzheimer's disease using molecular genetics. J ournal of 
the American Medical Association, 277: 825-831.

12. McKhann G, Drachman D, Folstein $M$, Katzman R, Price D \& Stadlan EM (1984). Clinical diagnosis of Alzheimer's disease: Report of the NINCDS-ADRDA Work Group under the auspices of Departments of Health and Human Services Task Force on Alzheimer's disease. Neurology, 34: 939-944.

13. Chamberlain J C, Thorm J A, Oka K, Galton DJ \& Stocks J (1989). DNA polymorphisms at the lipoprotein lipase gene: associations in normal and hypertriglyceridaemic subjects. Atherosclerosis, 79: 8591.

14. Lahiri DK \& Nurnberger J I (1991). A rapid non-enzymatic method for the preparation of HMW DNA from blood for RFLP studies. Nucleic Acids Research, 19: 5444.

15. Maekawa B, Cole TG, Seip RL \& Bylund D (1995). Apolipoprotein E genotyping methods for the clinical laboratory. J ournal of Clinical Laboratory Analysis, 9: 6369.

16. Roff DA \& Bentzen P (1989). The statistical analysis of mitochondrial DNA polymorphisms: $\chi^{2}$ and the problem of small samples. Molecular Biology and Evolution, 6: 539-545.

17. Templeton AR (1987). The general relationship between average effect and average excess. Genetics Research, 49: 6970.

18. Gerdes LU, Klausen IC, Sinm I \& Færgeman O (1992). Apolipoprotein E polymorphism in a Danish population compared to findings in 45 other study populations around the world. Genetic Epidemiology, 9: 155-167.

19. Knijff $P$ de, Maagdenberg AMJ M, Frants RR \& Havekes LM (1994). Genetic heterogeneity of apolipoprotein $E$ and its influence on plasma lipid and lipoprotein levels. Human Mutation, 4: 178-194.

20. Valveny N, Esteban E, Kandil M \& Moral P (1997). APO E polymorphism in Spanish and Moroccan populations. Clinical Genetics, 51: 354-356.

21. Lucotte G, Loirat F \& Hazout S (1997). Pattern of gradient of apolipoprotein $\mathrm{E}$ allele $* 4$ frequencies in Westem Europe. Human Biology, 69: 253-262.

22. Corbo RM, Scacchi R, Mureddu L, Mulas G \& Alfano G (1995). Apolipoprotein E polymorphism in Italy investigated in native plasma by a simple polyacrylamide gel isoelectric focusing technique. Comparison with frequency data of other European populations. Annals of Human Ge- netics, 59: 197-209.

23. Sepehrnia B, Kamboh MI, AdamsCampbell LL, Bunker CH, Nwankwo M, Majumder PP \& Ferrell RE (1989). Genetic studies of human apolipoproteins. $X$. The effect of the apolipoprotein E polymorphism on quantitative levels of lipoproteins in Nigerian blacks. American J ournal of Human Genetics, 45: 586-591.

24. Zekraoui L, Lagarde JP, Raisonnier A, Gérard N, Aouizérate A \& Lucotte G (1997). High frequency of the apolipoprotein $E^{*} 4$ allele in African Pygmies and most of African populations in Sub-Saharan Africa. Human Biology, 69: 575-581.

25. Bortolini MC, Silva J $r$ WA, Guerra DC, Remonatto G, Mirandola R, Hutz MH, Weimer TA, Silva MCBO, Zago MA \& Salzano FM (1999). African-derived South American populations: a history of symmetrical and asymmetrical matings according to sex revealed by bi- and uniparental genetic markers. American J ournal of Human Biology, 11: 551-563.

26. Saunders AM, Strittmatter WJ, Schmechel D, St. George-Hyslop PH, PericakVance MA, J oo SH, Rosi BL, Gusella J F, Crapper-McLachlan DR, Alberts MJ, Hulette C, Crain B, Goldgaber D \& Roses AD (1993). Association of apolipoprotein $\mathrm{E}$ allele $\mathrm{E}^{*} 4$ with late-onset familial and sporadic Alzheimer's disease. Neurology, 43: 1467-1472.

27. Farrer LA, Cupples LA, Haines J L, Hyman $B$, Kukull WA, Mayeux R, Myers RH, Pericak-Vance MA, Risch N \& Van Dujin CM (1997). Effects of age, sex, and ethnicity on the association between apolipoprotein E genotype and Alzheimer's disease - A meta-analysis. J ournal of the American Medical Association, 278: 13491356.

28. Kervinen K, Savolainen M J, Salokannel J , Hynninen A, Heikkinen J, Ehnholm C, Koistinen MJ \& Kesäniemi YA (1994). Apolipoprotein $\mathrm{E}$ and $\mathrm{B}$ polymorphisms longevity factors assessed in nonagenarians. Atherosclerosis, 105: 89-95.

29. Louhija J, Miettinen HE, Kontula K, Tikkanen MJ, Miettinen TA \& Tilvis RS (1994). Aging and genetic variation of plasma apolipoproteins - Relative loss of the apolipoprotein E4 phenotype in centenarians. Arteriosclerosis and Thrombosis, 14: 1084-1089.

30. Haviland MB, Lussier-Cacan S, Davignon J \& Sing CF (1995). Impact of apolipoprotein $E$ genotype variation on means, variances, and correlations of plasma lipid, lipoprotein, and apolipoprotein traits in octogenarians. American J ournal of Medi- cal Genetics, 58: 315-331.

31. Corder EH, Lannfelt L, Viitanen $M$, Corder LS, Manton KG, Winblad B \& Basun H (1996). Apolipoprotein E genotype determines survival in the oldest old (85 years or older) who have good cognition. Archives of Neurology, 53: 418-422.

32. Pablos-Méndez A, Mayeux R, Ngai $C$ Shea $S \&$ Berglund L (1997). Association of apo $E$ polymorphism with plasma lipid levels in a multiethnic elderly population. Arteriosclerosis, Thrombosis, and Vascular Biology, 17: 3534-3541.

33. Xhignesse $M$, Lussier-Cacan $S$, Sing CF, Kessling AM \& Davignon J (1991). Influences of common variants of apolipoprotein $\mathrm{E}$ on measures of lipid metabolism in a sample selected for health. Arteriosclerosis and Thrombosis, 11: 1100-1110.

34. Zaman MM, Ikemoto S, Yoshiike N, Date C, Yokoyama T \& Tanaka H (1997). Association of apolipoprotein genetic polymorphisms with plasma cholesterol in aJ apanese rural population. Arteriosclerosis, Thrombosis, and Vascular Biology, 17: 3495-3504.

35. Boer JMA, Ehnholm C, Menzel $H$, Havekes LM, Rosseneu M, O'Reilly DSJ \& Tiret L (1997). Interactions between lifestyle-related factors and the apoE polymorphism on plasma lipids and apolipoproteins - The EARS study. Arteriosclerosis, Thrombosis, and Vascular Biology, 17: 1675-1681.

36. Bohnet $K$, Regis-Bailly $A$, Vincent-Viry $M$, Schlenck A, Gueguen R, Siest $G \&$ Visvikis $S$ (1996). Apolipoprotein E genotype E*4/ $E^{*} 2$ in the STANISLAS Cohort Study Dominance of the $E^{*} 2$ allele? Annals of Human Genetics, 60: 509-516.

37. Sandholzer $C$, Delport R, Vermaak $H$ \& Utermann $G$ (1995). High frequency of the apo E4 allele in Khoi San from South Africa. Human Genetics, 95: 46-48.

38. Robitaille N, Cormier G, Couture R, Bouthillier D, Davignon J \& Pérusse L (1996). Apolipoprotein E polymorphism in a French Canadian population of northeastern Quebec: allele frequencies and effects on blood lipid and lipoprotein levels. Human Biology, 68: 357-370.

39. Valdez R, Stern MP, Howard BV \& Haffner SM (1995). Apolipoprotein E polymorphism and insulin levels in a biethnic population. Diabetes Care, 18: 992-1000.

40. Muros M \& Rodríguez-Ferrer C (1996). Apolipoprotein E polymorphism influence on lipids, apolipoproteins and Lp(a) in a Spanish population underexpressing apo E4. Atherosclerosis, 121: 13-21.

41. Gregg RE, Zech LA, Schaefer EJ \& Brewer 
J r HB (1981). Type III hyperlipoproteinemia: defective metabolism of an abnormal apolipoprotein E. Science, 211: 584586.

42. Ghiselli G, Schaefer EJ, Zech LA, Gregg RE \& Brewer J r HB (1982). Increased prevalence of apolipoprotein E4 in type $\mathrm{V}$ hyperlipoproteinemia. J ournal of Clinical Investigation, 70: 474-477.

43. Schaefer EJ, Lamon-Fava S, J ohnson S, Ordovas J M, Schaefer MM, Castelli WP \& Wilson PWF (1994). Effects of gender and menopausal status on the association of apolipoprotein $E$ phenotype with plasma lipoprotein levels. Arteriosclerosis and Thrombosis, 14: 1105-1113. 